\title{
A DOMINANT MUTANT MOSAIC HOUSE MOUSE
}

\author{
N. R. BHAT \\ Deportment of Genetics, Combridge
}

\section{INTRODUCTION}

Received 28.i.49

Colour mosaicism has been frequently observed in several different plants. In the animal kingdom Drosophila has provided more cases than mammals. The total number of mosaics reported so far among rodents-guinea-pigs, rats, rabbits and house mice-is about twentyfour, the mouse mosaics being only eight. Most of them have been discussed in detail by Wright (1926) and Dunn (1934).

Mosaicism observed in animals is either only somatic or both germinal and somatic, there being little chance of detecting it visually when only the germinal cells are affected. The mosaics throw light on several points, e.g. (I) the stages of development of an organism in which mutations can occur, (2) the course of differentiation of the epidermal tissue and the consequent distribution of body colours in animals, and (3) the nature of multiple allelism. In addition they may prove to be the source of entirely new mutations.

The following is an account of a "germinal-and-somatic" mosaic in the house mouse resulting from a reverse mutation at the agouti locus, of the gene $a$ (non-agouti) to $A^{L}$ (light-bellied agouti).

\section{THE ORIGIN OF THE MOSAIC}

In line $\mathrm{I} 7$, one of the $2 \mathrm{I}$ inbred lines being built up in this laboratory which was being run on a non-agouti $(a a)$ background, there arose an altogether new type of animal possessed of irregular agouti-like markings on the back. The mouse was a female and was one of the seven young born of mating No. $5^{6}$ in its first litter. The line contained already the three factors, $F u$ (fused tail), se $d$ (short ear and dilute combined in coupling and treated as only one factor) and wo (wavy hair). Mating No. $5^{6}$ was a test cross effected after the simultaneous introduction of two new factors, $s$ (recessive pied) and te (light head).

To all appearances, the new animal was an agouti-non-agouti mosaic. The agouti-like markings were distributed on the dorsolateral areas, haunches, rump near the base of the tail, shoulders and cheeks and round about the eyes. In each part of the body, they were separated by wide patches of ground colour (non-agouti), as in the case of Dunn's (1934) black-chocolate mosaic. On the sides they 
were long and slender and, being more regular than elsewhere, looked more or less like the yellow bands of a tiger. The hair constituting the markings possessed subterminal yellow bands similar to the agouti hair. A wide irregularly round portion between the hind legs including the genitalia was creamy white, the remaining portion of the ventral side being an admixture of black and creamy hair in different proportions. A coloured photograph of the mouse (as mounted) is given in plate I.

The appearance of such an animal would have been remarkable in any stock, the more so because it came from an inbred line which was non-agouti from the start. Even a far-fetched hypothesis that the animal could possibly be the product of the mating of her mother with either an " $A$ " (wild-type agouti) or an " $A^{L}$ " (light-bellied agouti) male from outside the line was untenable as there was backcross segregation for the three line factors, se $d$ and $w v_{1}$ in the litter in which the mouse was born, and also the young were $+/ s$ (heterozygous pied). The combination of all these four factors did not exist elsewhere in the laboratory. It looked probable that the mouse was a mosaic of agouti and non-agouti, though the possibility of it representing an altogether new factor could not be excluded.

\section{INVESTIGATION}

The father of the mosaic doe having been killed already according to the regime of the line, she was mated to her brother. From this mating she gave, in all, 27 young which were all non-agouti $(a a)$. Next, she was mated to a son from her brother. From this new mating she bore 36 young of whom two resembled " $A^{L}$ " mice almost entirely.

The difference in the coat pattern of the two offspring from the second mating from that of their mother, as well as the fact that they were too few $\left(2 / 6_{3}\right)$ to represent the recessive class in a monofactorial segregation $\left(\chi^{2}=7 \cdot 26\right)$, confirmed the impression that the original mouse was a mosaic. Also, it was evident that it was both germinal and somatic. There being no possibility of the markings, if they were agouti, having resulted from the loss either of a chromosome or a locus, it was most certainly mutational in a strict sense.

This being the case, it was of immediate interest to know (I) whether the mutation was at the agouti locus, (2) whether it was dominant or recessive and if dominant, (3) whether it was a reversion from $a$ to $A^{L}$. As the mutants were almost wholly like $A^{L}$ animals it appeared most probable that it was a case of the last kind.

To complete the life of the mosaic doe, she was further mated to one of the above $A^{L}$-like sons. This mating yielded 29 young 16 of which were like the father.

The mosaic doe thus produced altogether 92 young.

I began by seeking an answer to the question, whether the mutation was at the agouti locus. As the agouti locus involves multiple 
alleles, the best course was to produce for tests animals heterozygous at the locus with an allele which could not produce the phenotypic effect of either $a$ or $A^{L}$. Such an allele was only $a^{t}$. At the same time, it was preferable to use an undulated (un/un) mouse for the outcross as this factor is known to be very closely (about 5 per cent.) linked to the agouti locus. The question under investigation could be finally solved (I) by testing the mutant-like progeny from the outcross with aa animals, if the mutation proved to be dominant and (2) by sib matings between the young, if recessive. In either case aa mice could appear among the progeny only if the mutation was elsewhere than at the agouti locus.

One of the $A^{L}$-like sons from the second mating of the mosaic was outcrossed to (what was thought to be a homozygous black and tan and undulated, i.e. $a^{t} u n / a^{t}$ un doe, but which in fact proved to be) an $a^{t}$ un/a un doe. This mating yielded 9 mice out of which 4 were like light-bellied agouti (either $A^{L}+1 a^{t}$ un or $A^{L}+/ a$ un). The mutation was, therefore, dominant. For a critical test, crosses were made between two of the above four (which were later proved to carry $a^{t}$ ) and a un/a un mice. None of the two test matings produced any a (nonagouti) mice amongst their aggregate progeny of 66 , proving beyond doubt that the mutation was at the agouti locus. In all probability, it was a reversion of the gene $a$ to $A^{L}$ or an equivalent allele. An alternative interpretation that the mutation was a mimic of $A^{L}$ but very closely linked to it, though not inadmissible, is too far fetched to be of any special significance.

Strangely enough, the two test matings are dissimilar in their performance. One of them has produced 32 mice, I 6 of which are like the mutant parent and the other $16\left(a^{t} u n / a^{t} u n\right)$ black and tan with undulated tails. This is exactly according to expectation. The other, however, has yielded only 7 mutant-like young out of its total progeny of 34. Two crossovers with undulated, one $a^{t}+$ and the other $A^{L}$ un appears from this mating. The disproportion between the number of $A^{L}$ and $a^{t}$ mice produced by the latter mating is difficult to understand.

\section{DISCUSSION}

The mosaic described above is altogether new in two different respects. First, it is the first observed in the house mouse involving the agouti locus. Of the eight mosaics reported so far in this animal five involved black and chocolate (Pincus, 1929; Fisher, 1930; Bittner, 1938), two involved pink eye (Feldman, 1935) and one Chinchilla (Dunn, I934). Of them the last and Fisher's tricolour proved to be germinal. None pertained to the agouti factor. Secondly, the new mosaic is not only germinal but also represents a reverse mutation at the agouti locus from the gene $a$ (non-agouti) to $A^{L}$ (light-bellied agouti), a phenomenon new to the literature of the house mouse, and also extremely rare among mammals. 
Dunn (1934) has made a survey of the twenty-one mosaics, including his own, reported till then among rodents. Of them eighteen were non-genetic and only three "germinal-somatic." Another three (Feldman, I935; Bittner, I938) somatic mosaics have been reported since. The three of the latter category were :-

(I) Wright's dilute-intense mosaic guinea-pig,

(2) Dunn's black-chocolate mosaic mouse and

(3) Fisher's tricolour mosaic.

The one under discussion is the fourth of this kind.

The association detected by Dunn between the appearance of mosaics and the factor $s$ (recessive piebald) is noticeable even in this case. Dunn pointed out that, first, all except a doubtful one-Castle's (I912) mosaic guinea-pig - of the nineteen purely somatic mosaics had occurred in white-spotted animals and, secondly, that in fourteen of the above cases which were clear, the mutant area appeared " as a single patch as would be expected if a single abnormal cell division involving non-division or non-disjunction of one chromosome had occurred in the direct ancestry of this tract." Suggesting that somatic mitosis may more frequently be irregular in animals with white spotting.

Three out of the four germinal-somatic mosaics, including the one under discussion, have been non-spotted, though at least the two in the house mouse were surely heterozygous for recessive pied. Fisher's germinal-somatic black-brown was homozygous recessive pied. The peculiar feature of all these four is that the new types of patches were widely separated in different parts of the body.

Both Wright and Dunn have been of opinion that such intermittent distribution of cells carrying the unchanged and the changed locus implies, firstly, that the "colour reaction of a cell is governed chiefly by its own genes" at least in mosaics and, secondly, that the patches of the new type of cells were initially united and their separation by areas of normal colour is the result of "differential growth rates or migrations in different directions of the tissues which compose the epidermis." These observations are more thoroughly confirmed in this case as the new tissue consists of cells in which the mutation is from the recessive allele to the dominant.

Lastly, the reverse mutation throws light on the nature of multiple allelism at the agouti locus. As is well known, the alleles are, $A^{Y}$ (yellow), $A^{L}$ (light-bellied agouti), $A$ (wild-type agouti), $a^{t}$ (black and $\tan$ ) and $a$ (non-agouti). Of these $A^{Y}$ being very different in its effects from the rest of the alleles may not be considered here. The dominance relationship between the other four is as below :-

$$
\begin{aligned}
& A^{L} \text { is dominant to } A, a^{t} \text { and } a \\
& a^{t},, \quad, \quad, a \\
& A,, \quad, \quad, a
\end{aligned}
$$


Now, in the case of multiple alleles, there is usually the alternative possibility of their being actually situated on very closely adjacent loci with extremely rare chances of the crossover types being found. Indeed, some of what were thought to be single multiple-allelic series for quite a long time have been found to be of the latter category, as follows :-

(I) Recently, Chai Pao Yu and Te Sun Chang (1948) have given an account of their investigations on the so-called multiple alleles determining the anthocyanin pigmentation in Asiatic cotton. Having started with 14 alleles they detected 6 new ones, 4 of which apparently resulted through recombination in the progenies of crosses involving the original genes. In at least one of the four cases crossing over is clearly established : both the recombinant as well as the parental types were recovered in the $F_{2}$ progeny. Thus, the 20 alleles have been shown to form at least three different series situated on very closely linked loci.

(2) Ernst (1942) explained the occurrence and frequencies of the various grades of calycanthemy ranging from $C^{V}$ (complete calycanthemy) to $c^{6-n}$ (almost normal green calyx) on a similar hypothesis of linkage and crossing over.

(3) An apparently well-authenticated crossover concerning the Rhesus factor in man was reported by Dr Glass at the International Genetic Congress, Stockholm (1948).

On the analogy of the above cases of intergenic crossovers the following two-loci hypothesis could be proposed to explain the multiple allelism at the agouti locus. The four alleles $A^{L}, A, a^{t}$ and $a$ affect two different parts of the body in the house mouse, viz. the back and the belly. It would, therefore, be reasonable to postulate that two different elements at the agouti locus are responsible for the colouration of these parts. $A^{L}$ would then represent the combination of two dominant alleles and $a$ of two recessives, $A$ and $a^{t}$ representing crossovers between the two elements.

The occurrence of the present reverse mutation is compatible with such an hypothesis only if the mutation from $a$ to $A^{L}$ affected the two supposed elements simultaneously. If such elements had nothing in common such a contingency might be regarded as too remote to be considered. In this case, however, the hypothetical elements are certainly closely adjacent, and also, presumably, of similar nature. Simultaneous mutation of homologous genes has been reported by Frankel (1949) in wheat.

\section{SUMMARY}

A mosaic house mouse with agouti markings arose in an inbred non-agouti ( $a a)$ line. Investigation proved it to be the result of a reverse mutation from $a$ to $A^{L}$ at the agouti locus. It is inferred that, if the agouti factor involves two closely adjacent loci, the mutation may have affected both of them. 
Acknowledgments.-I am indebted to Professor R. A. Fisher, Sc.D., F.R.S., for his guidance, and to $\mathrm{Mr} \mathrm{H}$. Mowl for his help in maintaining the stock and for looking after the test matings after I left the laboratory.

\section{REFERENCES}

BITTNER, J. J. I 932 .

A colour mosaic in the mouse.

7. Hered., 23, 421 .

DUNN, L. C. 1934 .

Analysis of a case of mosaicism in the house mouse.

7. Genet., 29, 31 7-326.

ERNST, A. 1942.

Gene mutations as causes of variations in penetration and expressiveness of a formanomaly proved by experimental pedigree research on calycanthemous primulas. Biol. Abstracts, 19, No. 12069 .

FELDMAN, H, W. 1935 .

A mosaic (dark-eyed intense-pink-eyed dilute).

7. Genet., 30, 383-388.

FISHER, R. A. $193 \%$.

Note on a tricolour (mosaic) mouse.

7. Genet., 23, 77-81.

FISHER, R. A. 1935 .

Evolution of dominance.

Biol. Rev., oo, II I-III.

FRANKEL, O. H. 1950.

A polymeric multiple gene change in hexaploid wheat.

Heredity, 4 (in the press).

GRUNEBERG, H. 1943.

Genetics of the Mouse. London: Cambridge University Press.

PINCUS, G. 1929 .

A mosaic (black-brown) coat pattern in the mouse.

7. Exp. Zool., 135, 323-356.

WRIGHT, s. 1926 .

Mutational mosaic coat patterns of the guinea-pig.

Genetics, 11, 333-351.

YU, C. P., AND CHANG, T. s. 1948.

Further studies on the inheritance of anthocyanin pigmentation in Asiatic cotton. 7. Genet., 49, 46-56. 


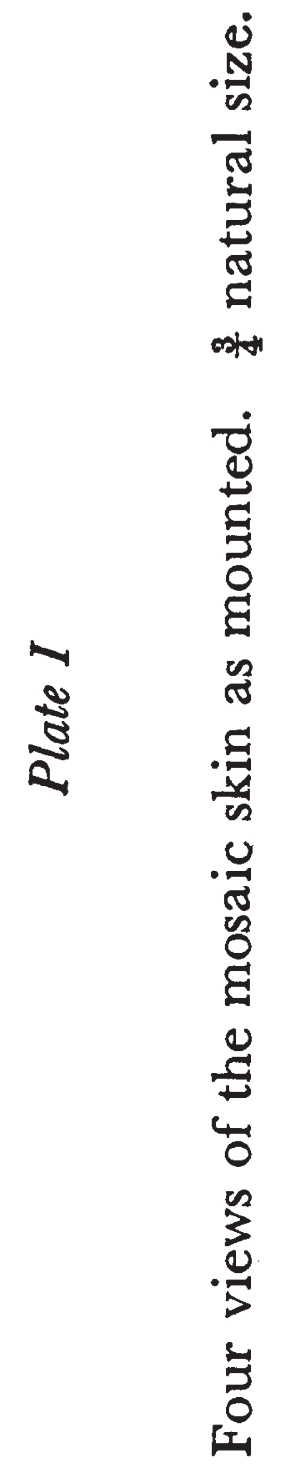


